This is a self-archived - parallel published version of this article in the publication archive of the University of Vaasa. It might differ from the original.

\title{
Valorizing the Human Capital Within Organizations: A Competency Based Approach
}

Author(s): Polo, Federica; Kantola, Jussi

Title: $\quad$ Valorizing the Human Capital Within Organizations: A Competency Based Approach

Year: $\quad 2019$

Version: Accepted manuscript

Copyright (C) 2019 Springer. This is a post-peer-review, pre-copyedit version of an article published in Advances in Human Factors, Business Management and Society. AHFE 2018. The final authenticated version is available online at: https://doi.org/10.1007/978-3-319-94709-9_6

\section{Please cite the original version:}

Polo, F. \& Kantola, J. (2019). Valorizing the Human Capital Within Organizations: A Competency Based Approach. In: Kantola J., Nazir S. \& Barath T. (eds.) Advances in Human Factors, Business Management and Society: Proceedings of the AHFE 2018 International Conference on Human Factors, Business Management and Society, July 21-25, 2018, Loews Sapphire Falls Resort at Universal Studios, Orlando, Florida, USA, 55-63. Advances in Intelligent Systems and Computing, vol. 783. Cham: Springer. https://doi.org/10.1007/978-3-319-947099_6 


\title{
Valorizing the human capital within organizations: a competency based approach.
}

\author{
Federica Polo* and Jussi Kantola* \\ * School of Technology and Innovation, University of Vaasa, Wolffintie 34, 65200 Vaasa, \\ Finland
}

*fpolo@uwasa.fi; jussi.kantola@uva.fi;

Reprinted by permission from Springer

Palgrave Macmillan; Advances in Human Factors, Business Management and Society by Jussi Ilari Kantola, Salman Nazir and Tibor Barath (editors). Copyright Holder: Springer Nature Switzerland AG, 209.

\begin{abstract}
Changes in the business environment and in the nature of work itself require the implementation of integrated and flexible methodologies in competencies' definition in order to valorize the human capital and achieve organizational targets in a future-oriented perspective. However, extant research suggests that the available approaches to competency definition are more focused on describing past behaviors than on anticipating future requirements. Therefore, this study endeavors to provide a competency-based model that supports the top management in the identification of the competencies employees should posses, highlighting crucial competencies that can translate the strategy and vision of the organization into behaviors, skills, and terms that people can easily understand and implement. The results of our explorative case study led us to identify a set of competencies (digital/ analytical/ technical/ adaptive/ combinative/ proactive), classified following the Knowledge Skills Attitudes (KSA) model, that collectively lead to a successful definition of future-oriented competencies.
\end{abstract}

Key words: competencies $\cdot$ competency based methodology $\cdot$ strategic change $\cdot$ human capital $\cdot$ competency definition $\cdot(\mathrm{KSA})$ model $\cdot$ participative approach

\section{Introduction}

Organizations operating in changing business environment face a double challenge: the adaptation and implementation of the new business strategy in the most effective and quick way possible, on one side, and the need to sustain competitive advantage on the long run, on the other side [9]. These two challenges do not involve only business and financial aspects but also the process and people within the organization [9]. Therefore, the identification of core competencies becomes a strategic leverage to face both challenges, and it has a crucial role in translating the strategy and vision of the organization into knowledge, skills, and attitudes (KSAs), terms that can be easily understood and implemented ([30]; [22]). Furthermore, the growth of competition and technological innovation entails a substantial transformation of the business environment and of the nature of work, shifting from a static perspective to a more flexible and dynamic way of operating [4]. As a consequence, work tasks and skills are subject to constant change and adaptation [11]. In this situation, the definition of core competencies becomes important to link individual knowledge, skills, and attitudes (KSAs) to the organizational strategy and goals. Therefore, the implementation of competency models supports organizations in identifying patterns of core competencies to better perform a specific job, organization, or sector [25]. However, the changes in business needs and in the nature of work have made the implementation of competency models more complicated than before [1]. In the literature there are several examples of competency models' implementation, nevertheless, most of them are mainly oriented on describing past behaviors rather than pointing out competencies needed in the future [1]. Although this approach is worthy in some 
specific situation, in a context characterized by change it brings the risk of immobility, providing a set of competency requirements that do not match the strategic orientation and goals of the organization.

Therefore, the aim of this research is to provide insights for the definition and implementation of a competency-based model, highlighting crucial competencies that can translate the strategy and goals into KSAs needed to work in a more effective way in the organization.

\section{The concept of competency}

In the literature, there are several definitions of competency and competence at different levels: individual, group and organization ([19]; [10]; [25]). Indeed, in most of the cases, the definition given depends on the context and the perspective advocated [7]. For some scholars, competency refers mostly to individual characteristics, behaviors and actions (e.g. [17]; [28]) while for others it includes team, process, and organizational capabilities (e.g. [1]) [19]. Furthermore, in many studies (e.g. [28]; [6]) competencies are defined as the sum of motives, traits, self- concepts, knowledge, skills, and behaviors identified through the comparison between average and superior performance or effective and ineffective performance in an organizational context [19]. However, applying this definition appears as a limitation to the broader understanding of competencies in a context where business is changing fast [24], as in modern organizations. Indeed, focusing on behaviors that have already occurred, provide information about the present or the past [10] with the risk that the identified competencies do not match the future

needs of the organization.

Furthermore, previous research shows how competencies are defined from different perspectives [2]. Most of the studies define competency from the individual perspective, considering the individual job as the principal unit of analysis (e.g. [28]; [15]; [13]). Nevertheless, changes in the business environment and in the organization of work (project orientation, teamwork...) imply a change of perspective, including the team and organizational level in the definition of competencies [1]; [14].

Organizational competencies or organizational core competencies are defined in the literature as the product of individual KSAs shared across employees within an organization [4]. Following this definition, individual KSAs, aggregated to the level of the organization, constitute a potential to sustain competitiveness and competitive advantage [30]. Therefore, in contexts characterized by change, it becomes important for organizations to define the core competencies required to support the strategy and the target of the firm and align them with the individual KSAs in the organization [1].

Hence, competency models help organizations in identifying organization-specific competencies and in the alignment of individual competencies with organizational competencies and strategic targets [21]. In the following paragraph, we describe what are the characteristics that competency models should have to facilitate the translation of the organizational strategy into individual KSAs and how they should be implemented to identify KSAs needed to work effectively in changing organizations.

\section{Competency based models}

Competency models can be defined as tools for the identification of KSAs needed to perform in a specific role; their implementation helps the business to meet the strategic objectives [15]. Nevertheless, Kaplan and Norton [12] point out as the translation of the business strategy into individual KSAs represents a challenge for organizations. This occurs because in most of the 
cases competencies are defined in a prescriptive way, merely as job descriptions rather than as predictors of future needs [27]. This approach to competencies definition limits the dynamic adaptation of the organization to the business strategy, especially in an environment characterized by change [30]. Indeed, new challenges, changes in products or services, changes in customer preferences have an impact on competency models making them quickly obsolete [21]. Moreover, competency models should be designed to support the strategic orientation of the company, where organizational core competencies represent the foundation of the strategy formulation process [5]. In light of these considerations, competency models should be developed to be interactive and adaptable to the organizational change and strategy [30]. In this situation, organizational learning becomes the key element for the company to ensure the dynamism of the process [5]. Analyzing competency models in light of organizational learning implies a shift of focus from the individual level to organizational level, including in the competency definition not only individual KSAs but also process competencies that combined with individual KSAs will bring positive organizational advantage [1] accelerating also individual, team, and organizational change [29].

In this study we propose a competency model based on the identification of strategic targets the company is going to achieve, challenging the single-job approach that implies identifying KSAs to better perform in a specific task [16]. Indeed, we consider the organization as a whole and we attempt to define some strategic competencies that will influence the achievement of organizational targets in the future. The core element of our analysis is considering together organizational strategic objectives and employees' characteristics in terms of KSAs deploying them through the support of some key actors within the organization. Indeed, despite is not possible to forecast with certainty future needs, executives and top managers can give some specific insights about new developments, business changes and needs [18]. Involving them in the competencies definition is crucial for the reliability of the results [3]. Another crucial element coming from the literature is the definition of the temporal horizon for the competencies identification. The perspective we adopted is a time frame of 5-10 Years [8]. Our analysis consists of a bottom-up approach [19], we started from the definition of business targets to the identification of organizational core competencies, concluding with the identification of individual KSAs categorized in generic competencies, job-specific competencies, and managerial competencies.

Training and development professionals are using competency models to clarify organisationspecific competencies to improve human performance and unify individual capabilities with organisational core competencies.

\section{Method}

Data have been collected in one case company with the aim of identifying competencies that will be needed in the future to work in an effective way in the organization. The methodology implemented consists of a qualitative analysis. Data have been collected through interviews. The duration of each interview was 30 minutes on average. 34 people have been interviewed in 4 different departments and all of them are covering high managerial positions (Directors, Presidents, General Managers).

Data have been elaborated and analyzed following the criteria proposed by Smith [26]. The first step has been developing broad descriptions out of the data collected through interviews. The second step was identifying the main focus areas that have been categorized into four groups and that in our case correspond to the business targets and strategic orientation of the company in the next 5-10 Years. The following step was identifying common patterns and connections within the thematic areas. Specifically, we identified within the four main groups the related organizational core competencies from which we deployed the individual KSAs. The last step has been corroborating evidence clustering individual KSAs in generic competencies, technical competencies, and managerial competencies. The results have been 
discussed with experts within the organization in different sessions to counterproof their robustness and improve their reliability.

\section{Results}

The results obtained through the analysis consist of a detailed picture of the future orientation of the organization, starting from the business targets to the individual KSAs needed to achieve those targets. Fig1 describes the process of implementation of the competency model and the main elements emerged from the competency model implementation. Specifically, the four strategic targets identified are:

- Digitalization: what came out from the interviews is that the digitalization process is not only about technology (a basic understanding of technology will still be needed) but is more related to find new agile ways to adapt technology to the business needs, in order to create new business models and to make operations more efficient. From the technical standpoint, the digital transformation will affect the competencies in the engineering sector, indeed the challenge will be combining mechanical and electrical engineering with the digital transformation. Most of the respondents think that one of the priorities of the digitalization process is related to the development of a mindset that enables the digital transformation.

- Energy field: a key factor in the energy field in the next years will be the combination of different sorts of energy through big infrastructure projects (e.g. solar and power plants). The company will need to have a deep understanding of the energy process and market, and of the different players in the energy sector, in order to commercialize energy projects and develop the sector finding innovations. Furthermore, the focus will be on the energy storage and gas transportation as well as knowledge related to the environment and emissions.

- Production and services: in the future, there will be an increased need in terms of services related to the products as updating and upgrading products during their life cycle. To enable this long-term support the company will need to have a good product and system understanding. Another crucial aspect is the modularization of the products. In the future, there will be needed competencies related to modularization in order to create products in line with the customer needs, giving a broader choice to the client and increasing the efficiency of the production.

- Business and technology: there will be the need of developing both business understanding and technical capabilities. Indeed, to increase operational efficiency, the company will need to combine business and engineering competencies, developing business mindset in technical people - in order to use and adapt technology to create new business - and providing technical knowledge to business and salespeople, in order to better understand the products and solutions of the company. Moreover, a strategic mindset is required in all business functions, in particular in terms of understanding how to enter new businesses, and ability to make market analysis.

On the basis of these four strategic elements deployed in organizational core competencies we identified the main characteristics that the "employee and the manager of tomorrow" should have to work in the company.

In the next years, there will be required professionals with different characteristics. On one hand, there will be the need of technical professionals in the area of expertize, possessing according to their job: digital knowledge, computer and computing knowledge, electric and electronic knowledge, automation knowledge, or energy-related knowledge. On the other hand, there will be the need of more adaptable and communicational people, able to create new business occasions, bring innovation into the organization. 
What emerged from the analysis of the interviews is that general competencies are considered crucial within the organization. Communication among people and team members is considered a key element to maintain a good working climate, some people are better communicators by nature but all people should learn how to communicate in an efficient way. Furthermore, employees need to be prepared to work in a global network as well as in a virtual environment. Therefore, they need to develop good social skills and social skills in a virtual environment that imply different ways of managing the communication as well as the awareness and understanding of the multicultural context in which the communication takes place.

The work dimension nowadays is the team, therefore the "employee of tomorrow" needs to be a good team player: discussing openly, sharing, information and proposing solutions, developing good and effective reporting skills. The good team player is the one able to work independently, sharing information with the team when needed, and willing to develop him/her self and the colleagues. Furthermore, for the first time in history there will be four different generations simultaneously in the work environment, with their characteristics, background and way of operating. Therefore the "employee of tomorrow" needs to be able to adapt and understand other people characteristics and needs.

Moreover, employees will need to be able to manage their own work, meeting deadlines, prioritizing things while respecting a good quality level. They will need to be meticulous in searching for the right information and ready to exchange information within the company among different departments. The ability to sell their own added value within the team and in the organization is well regarded, as well as the ability to work as part of a system with analytic mindset and understanding the whole logic. Innovativeness is one of the main requirements of the company, together with the ability of analyzing situations optimistically but with a critical eye, conducting analysis at different levels.

Regarding the "manager of tomorrow", we classified the characteristics he/she should have in three main areas. The first area has been defined leadership skills. Indeed, the "manager of tomorrow" will not only be an expert in his/her field but he/she will have the ability to coach and lead the team, promoting a good working climate, focusing on people's needs, helping them to grow. He/she will coordinate the group giving autonomy and responsibility to people, not controlling them. Moreover the "manager of tomorrow" will be able to connect different competencies, seeing the entire picture and combining factors. He/she should be able to support problem solving and involve the team members in decision- making. 

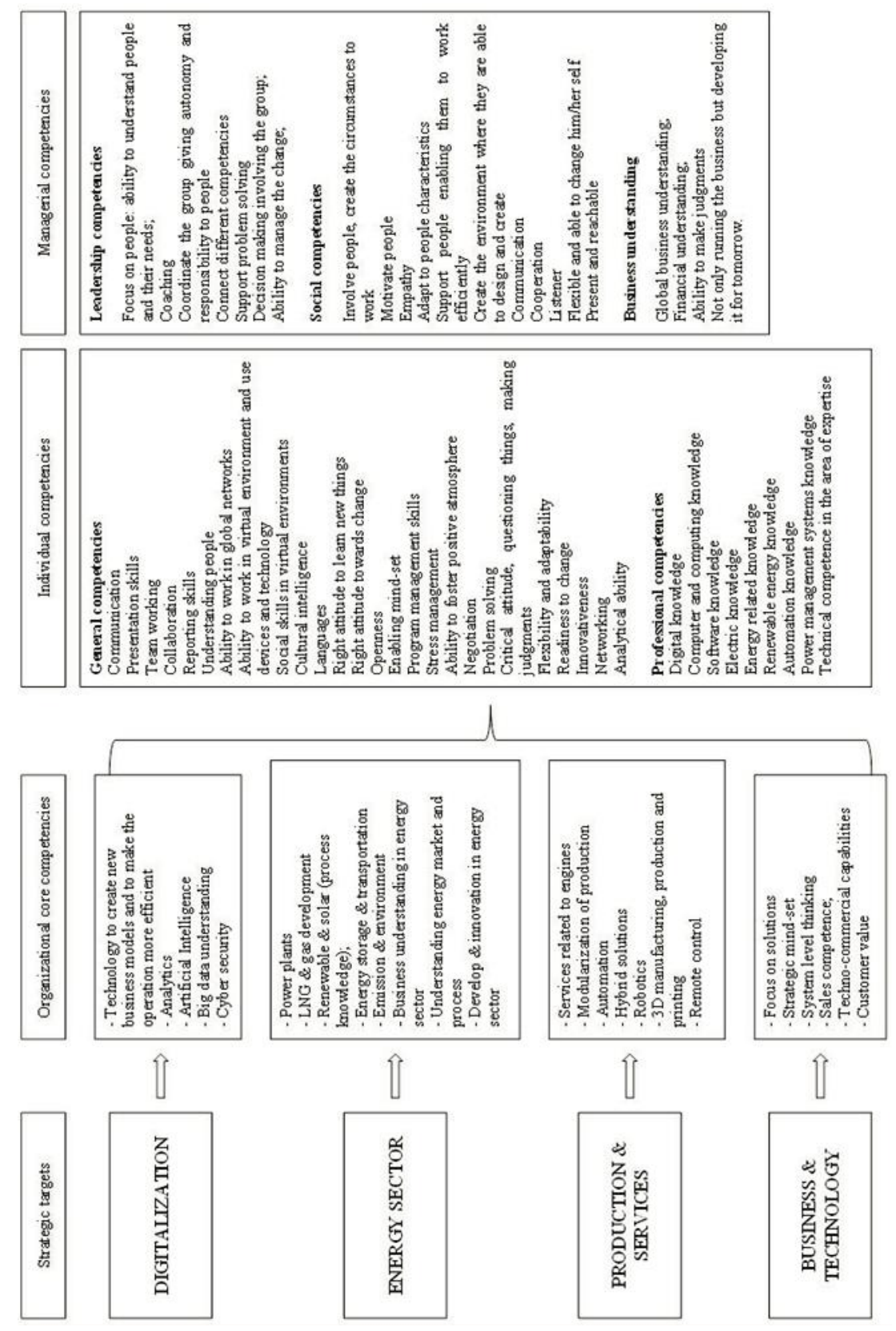

Fig1: Implementation of the competency model and main output

The second area of competencies we identified regards social skills. The "manager of tomorrow" will be able to involve people, creating the right circumstances to work and motivating them. Being emphatic and considering people as individuals, adapting his/her style to the people characteristics, will be crucial to enable the employees to work in a good environment and to achieve results. Therefore, the manager should also have good communication skills, adopting new ways of communicating and sharing information, and the ability to listen to people and understand their needs.

Finally, the third area identified is defined as business competencies. Indeed, the "manager of tomorrow" must have a strong global business understanding and financial understanding, and the ability of combining factors and making judgments. Not only coordinating the business in the present but developing it for the future. 
The change in business needs implies a change of perspective also in the approach to the human factor within organizations. Managers and executives have to consider that the new characteristics of business require the re-alignment of organizational and individual competencies [30]. Employees need to be not exclusively highly skilled but adaptable and ready to change, able to learn quickly and communicate effectively [20]. In this scenario, the implementation of competency models facilitates the identification of a set of competencies on the basis of the business strategy. Therefore, in this chapter we pointed out how through the implementation of a competency model tailored on the case organization, it is possible to identify the main characteristics the "employee of tomorrow" and on the "manager of tomorrow" should have on the basis of the future strategic orientation and targets of the company. Moreover, the results obtained through this research can be read through the concept of learning organization. Indeed, an organization able to adapt to new requirements, improving its ability to develop new competencies and support individuals and teams in achieving results is considered a learning organization [23].

\section{References}

1. Athey, T. R., Orth, M. S.: Emerging competency methods for the future. Human resource management, 38(3), 215-225 (1999)

2. Boon, J., \& Van der Klink, M.: Scanning the concept of competencies: how major vagueness can be highly functional. In Perspectives on learning in the workplace. Proceedings Second Conference on HRD Research and Practice Across Europe, 299-307 (2001)

3. Campion, M. A., Fink, A. A., Ruggeberg, B. J., Carr, L., Phillips, G. M., Odman, R. B.: Doing competencies well: Best practices in competency modeling. Personnel Psychology, 64(1), 225$262(2011)$

4. Dai, G., Liang, K.: Competency modeling research and practice in China: a literature review. Journal of Chinese Human Resources Management, 3(1), 49-66 (2012)

5. Fleury, A., Tereza Fleury, M. Competitive strategies and core competencies: perspectives for the internationalization of industry in Brazil. Integrated Manufacturing Systems, 14(1), 16-25 (2003)

6. Gangani, N. T., Mc Lean, G. N., Braden, R. A.: Competency-based Human Resource Development Strategy. Academy of Human Resource Development Annual Conference, Austin, TX, 4-7 March, Proceedings 2, 1111-1118 (2004)

7. Garavan, T. N., McGuire, D.: Competencies and workplace learning: some reflections on the rhetoric and the reality. Journal of Workplace learning, 13(4), 144-164 (2001)

8. Gow, K., McDonald, P.: Attributes required of graduates for the future workplace. Journal of Vocational Education and Training, 52(3), 373-396 (2000)

9. Gratton, L., Hope-Hailey, V., Stiles, P., Truss, C.: Linking individual performance to business strategy: The people process model. Human Resource Management, 38(1), 17-31 (1999)

10. Iles, P.: Employee resourcing. Human resource management: A critical text, 133-164 (2001)

11. Joiner, B.: Creating a culture of agile leaders: a developmental approach. People \& Strategy, 32 (4), 28-35 (2009) 
12. Kaplan, R. S., Norton, D. P.: How to implement a new strategy without disrupting your organization. Harvard business review, 84(3), 100 (2006)

13. Klink, M. R., Van Der Boon, J., \& Bos, E.: The investigation of distinctive competencies within professional domains. In Proceedings of the First Conference of HRD Research and Practice Across Europe, Kingston University, 105-14 (2000)

14. Lahti, R. K.: Identifying and integrating individual level and organizational level core competencies. Journal of Business and Psychology, 14(1), 59-75 (1999)

15. Lucia, A. D., Lepsinger, R.: Art \& science of competency models. San Francisco, CA: JosseyBass (1999)

16. Mansfield, R. S.: Building competency models: Approaches for HR professionals. Human Resource Management (1986-1998), 35(1), 7 (1996)

17. McClelland, D. C.: Testing for competence rather than for "intelligence".

American psychologist, 28(1), 1 (1973)

18. Polo, F.: Unboxing the key human competencies for successful servitization. In Kohtamäki, M., Baines, T., Rabetino, R., Bigdeli, A.,: Facilitating Servitization: practices and tools for managing service transition, Palgrave Macmillan (in press)

19. Robinson, M. A., Sparrow, P. R., Clegg, C., Birdi, K.: Forecasting future competency requirements: a three-phase methodology. Personnel Review, 36(1), 65-90 (2007)

20. Rodriguez, D., Patel, R., Bright, A., Gregory, D., Gowing, M. K.: Developing competency models to promote integrated human resource practices. Human Resource Management, 41(3), 309-324 (2002)

21. Rothwell, W. J., Lindholm, J. E.: Competency identification, modeling and assessment in the USA. International journal of training and development, 3(2), 90-105 (1999)

22. Sanchez, J. I., \& Levine, E. L.: What is (or should be) the difference between competency modeling and traditional job analysis?. Human Resource Management Review, 19(2), 53-63 (2009)

23. Senge, P. M.: The fifth discipline: The art and practice of the learning organization. New York: Doubleday/Currency (1990). (1990a)

24. Shackleton, V.: Using a competency approach in a business change setting. Designing and achieving competency. Boam, R. and Sparrow, P.(Eds.), McGraw- Hill, London (1992)

25. Shippmann, J. S., Ash, R. A., Batjtsta, M., Carr, L., Eyde, L. D., Hesketh, B., ... Sanchez, J. I.: The practice of competency modeling. Personnel psychology, 53(3), 703-740 (2000)

26. Smith, W. K.: Dynamic decision making: A model of senior leaders managing strategic paradoxes. Academy of Management Journal, 57(6), 1592- 1623 (2014)

27. Sparrow, P. R.: Organizational competencies: Creating a strategic behavioral framework for selection and assessment. International handbook of selection and assessment. Chichester: John Wiley (1997) 
28. Spencer, L.M., McClelland, D.C., Spencer, S.M.: Competency Assessment

Methods: History and State of the Art, Hay/McBer, Boston, MA (1992).

29. Ulrich, D.: Human resource champions: The new agenda for adding value and delivering results. Harvard Business School Press, Cambridge, MA (1997)

30. Vakola, M., Eric Soderquist, K., Prastacos, G. P.: Competency management in support of organizational change. International Journal of Manpower, 28(3/4), 260-275 (2007) 